\title{
Influence of Music Intervention on Emotional Control and Mental Health Management Self-efficacy of College Students
}

\author{
https://doi.org/10.3991/ijet.v16i20.26511
}

Xiujun $\mathrm{Xu}$

Shijiazhuang Preschool Teachers College, Shijiazhuang, China

xxjun002@126.com

\begin{abstract}
Music can induce strong emotions and psychological changes. The emotional control and mental health management of college students are greatly affected by gender, family background, grade, and other factors. Through music intervention, this paper explores how music-induced emotions influence the emotional control and mental health management self-efficacy of college students. The results show that positive music promotes the control of positive emotions, as positive music can give full play to active emotions; negative music both controls and enhances the negative emotions of college students; music intervention significantly affects the pleasantness dimension of the mental health of college students, but insignificantly affects the arousal dimension. The research findings lay a basis for further studies on emotional control and mental health management of college students.
\end{abstract}

Keywords-emotional control, mental health, music intervention, pleasantness, arousal, self-efficacy

\section{Introduction}

Emotional control has a few features as such novelty, validity, and authenticity [1, 2]. The novelty feature of emotional control is an indicator of emotional creativity, which can evaluate the novelty level of an emotional response compared with typical emotional responses in society [3,4]. The imbalance of physical and mental development of college students often makes them impulsive, weak-willed, and very emotional $[5,6]$. The heavy school pressure, exam pressure, and employment pressure can also cause them to show negative emotions, which can seriously affect their physical and mental development [7, 8]. Positive emotions can invigorate emotions, improve mental health, and thereby enhancing students' self-confidence and good learning habits and achieving positive results in all aspects [9, 10].

College students' emotions and mental states are usually greatly influenced by their academic performance, and such academic emotions are generated accompanying their learning activities [11-13]. Some researchers divided the academic emotions of college students into four categories based on arousal level and 
psychological resilience, namely: high resilience and high arousal, high resilience and low arousal, low resilience and high arousal, and low resilience and low arousal [1415]. Some researchers used nine emotional control indicators to evaluate nine kinds of emotions: pride, happy, hopeful, calm, relaxed, anxious, ashamed, bored, and helpless $[16,17]$.

In neuroscience, an important stimulus that could induce emotions is static visual images [18, 19]. Music has significant advantages acting as a tool of emotional intervention, it can induce strong emotions; compared with static visual images, the emotions induced by music are highly consistent with an individual's current emotional state $[20,21]$. Emotions and mental states induced by music intervention are not always positive, music intervention can induce both positive and negative emotions [22, 23]. Based on music intervention, this paper explores the influence of music-induced emotions on the emotional control and mental health management self-efficacy of college students.

\section{Status Quo of College Students' Academic Emotions and Psychological Resilience}

\subsection{Objectives and methods}

To figure out the status quo of college students' academic emotions and psychological resilience and the relationship between the two, our research team launched a questionnaire survey. The randomly chosen respondents are all college students from Jiangxi Nanchang University, China, a total of 500 questionnaires were sent out and 458 valid questionnaires were collected. Table 1 gives the basic information of the respondents, including gender, family situation, whether the respondent is a student cadre or not, and grade, etc. The students' emotions were divided into nine types: pride, joy, hope, peace, relief, anxiety, shame, boredom, and helplessness and scored separately; and the students' psychological resilience states were divided into four types: high resilience and high arousal, high resilience and low arousal, low resilience and high arousal, and low resilience and low arousal, and were scored as well. The full score for each question was 5 points, and the psychological resilience states and arousal levels were investigated using different questionnaires.

Table 1. Basic information of respondents

\begin{tabular}{|l|c|c|c|}
\hline Variable & Category & Number & Percentage/\% \\
\hline \multirow{3}{*}{ Gender } & Male & 261 & $56.99 \%$ \\
\hline \multirow{3}{*}{ Family situation } & Female & 197 & $43.01 \%$ \\
\cline { 2 - 4 } & Non poverty & 377 & $82.31 \%$ \\
\hline \multirow{2}{*}{ Student cadre } & Poverty & 81 & $17.69 \%$ \\
\hline \multirow{3}{*}{ Grade } & Yes & 69 & $15.07 \%$ \\
\cline { 2 - 4 } & No & 389 & $84.93 \%$ \\
\cline { 2 - 4 } & First grade & 96 & $20.96 \%$ \\
\cline { 2 - 4 } & Second grade & 121 & $26.42 \%$ \\
\cline { 2 - 4 } & Third grade & 129 & $28.17 \%$ \\
\cline { 2 - 4 } & Fourth grade & 118 & $25.76 \%$ \\
\hline
\end{tabular}




\subsection{Status quo of college students' academic emotions and psychological resilience states}

Figure 1 is a statistic of the status quo of college students' academic emotions. Obviously, the scores of positive academic emotions of college students are higher than those of negative academic emotions, and the scores of each dimension of the positive academic emotions are all higher than 3.5, among these dimensions, the score of the hope dimension is the highest, followed by the joy dimension. Figure 2 shows the status quo of college students' psychological resilience. Overall speaking, current college students' psychological resilience state is at an average level; the scores of the four dimensions of psychological resilience from high to low are: high resilience and high arousal $>$ low resilience and high arousal $>$ high resilience and low arousal $>$ low resilience and low arousal. Figure 3 shows the influence of various factors on college students' academic emotion and psychological resilience. Figure 3(a) is about the gender factor, clearly, the positive academic emotions of female students are significantly higher than those of male students, and the negative academic emotions of female students are generally higher than those of male students, too (except for the boredom dimension). Figure 3(b) is about the family situation factor, according to the figure, the positive academic emotions of students from non-poverty families are significantly higher than those from poverty families; the negative academic emotions of students from poverty families are higher than those from non-poverty families. In terms of the three dimensions of high resilience/high arousal, high resilience/low arousal, and low resilience/high arousal, the scores of students from non-poverty families are significantly higher than those from poverty families; while in terms of the low resilience/low arousal dimension, the average score of students from poverty families is higher than that of students from non-poverty families.

Figure 3(c) is about the student cadre factor. Cadre students' positive emotion dimensions are significantly higher than common students, and their negative emotion dimensions are lower than common students. In terms of the two dimensions of high resilience/high arousal and high resilience/low arousal, the scores of common students are higher; while in terms of the two dimensions of low resilience/high arousal and low resilience/low arousal, the scores of cadre students are higher, that is, the cadre students' psychological resilience is lower. Figure $3(\mathrm{~d})$ is about the grade factor, overall, the academic emotions of sophomore students are lower, the academic emotions of senior year students are the highest; the higher the grade, the better the psychological resilience. 


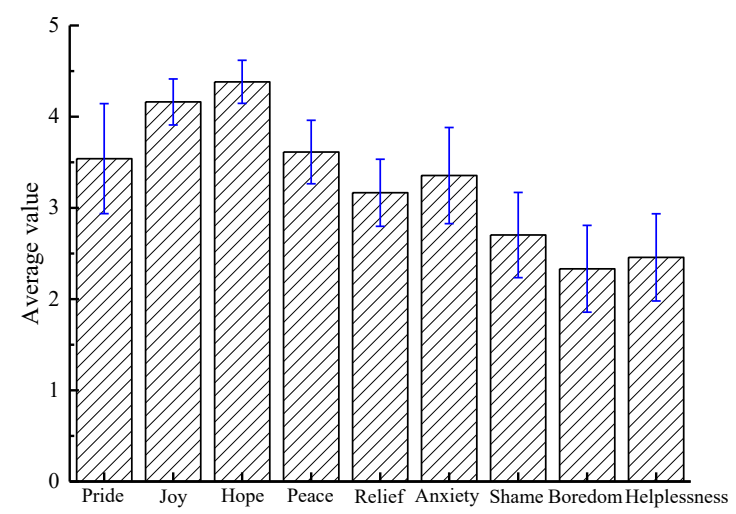

Fig. 1. Status quo of college students' academic emotions

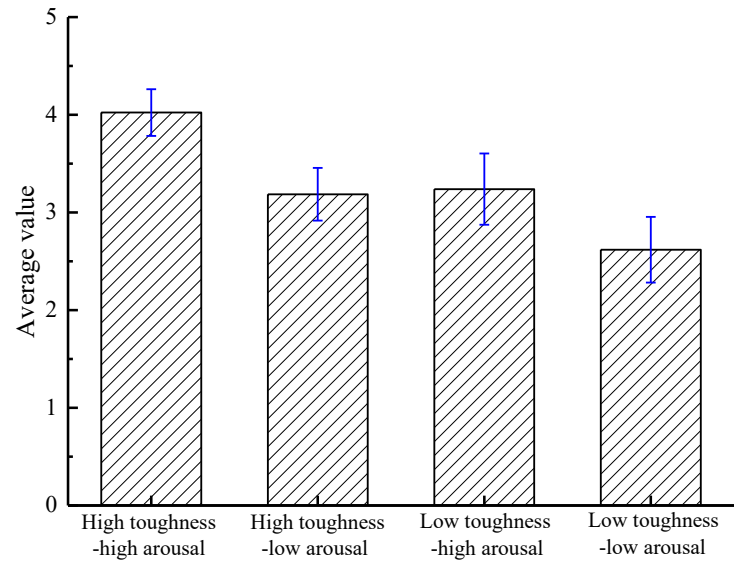

Fig. 2. Status quo of college students' psychological resilience
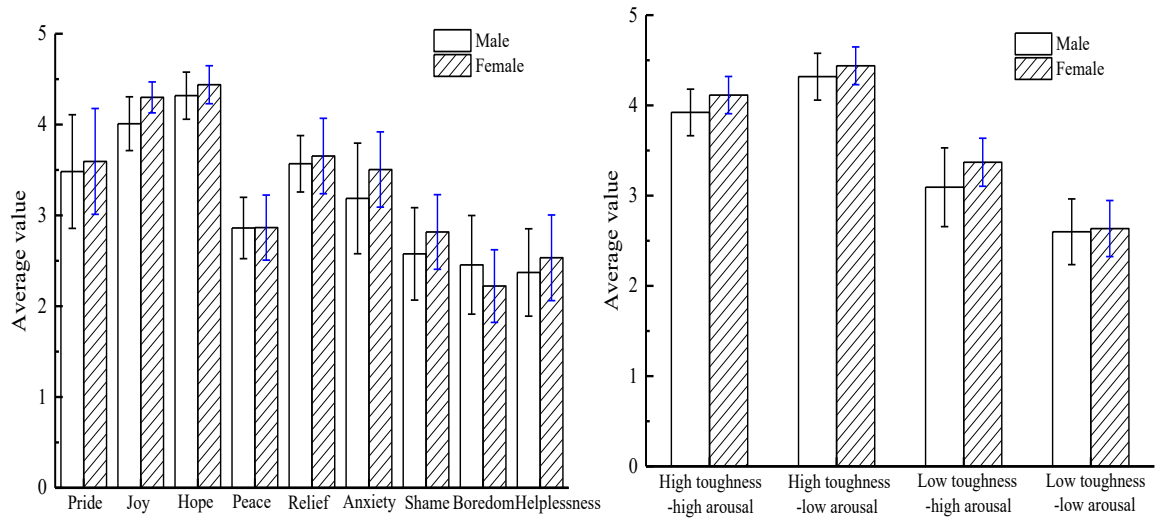

a) Gender factor 
Paper-Influence of Music Intervention on Emotional Control and Mental Health Management...
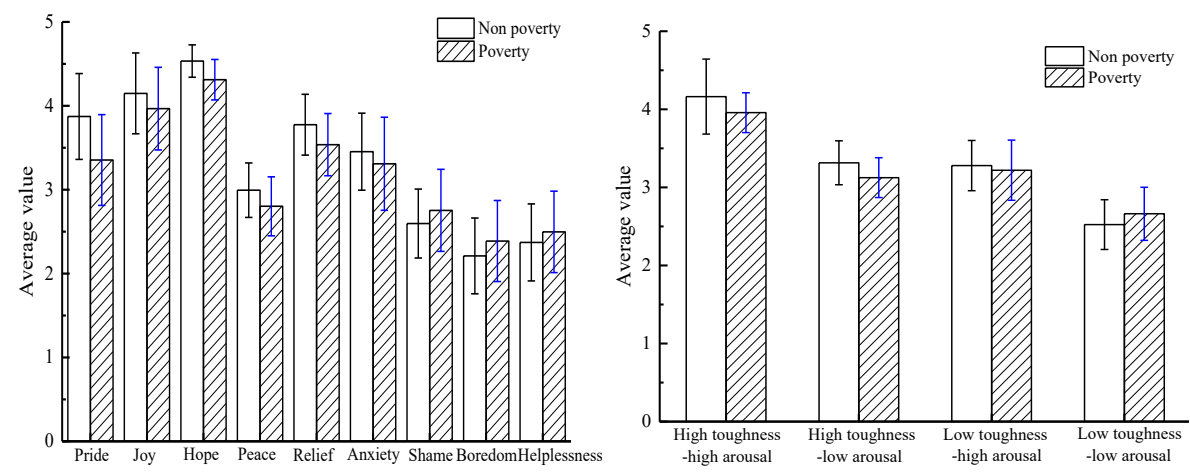

b) Family situation factor
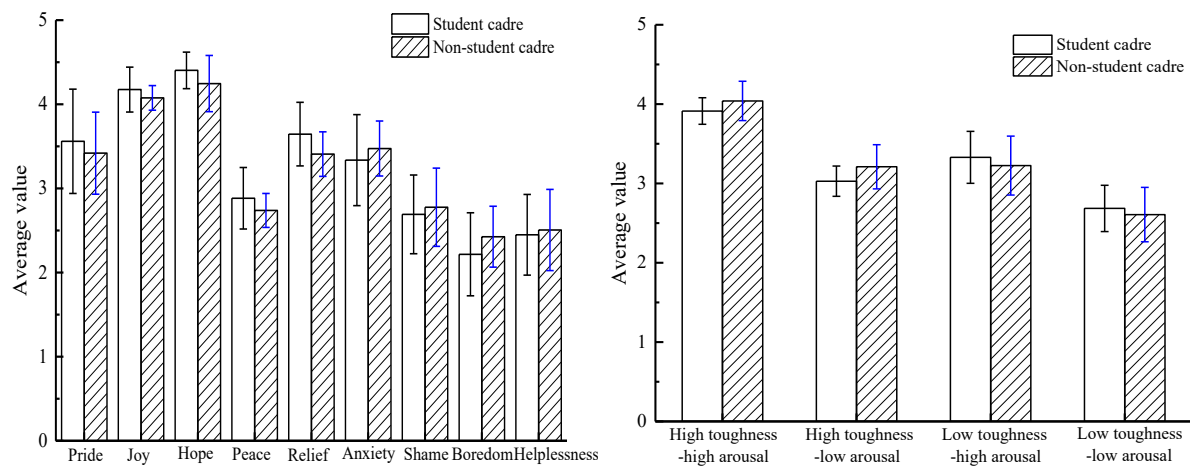

c) Student cadre factor
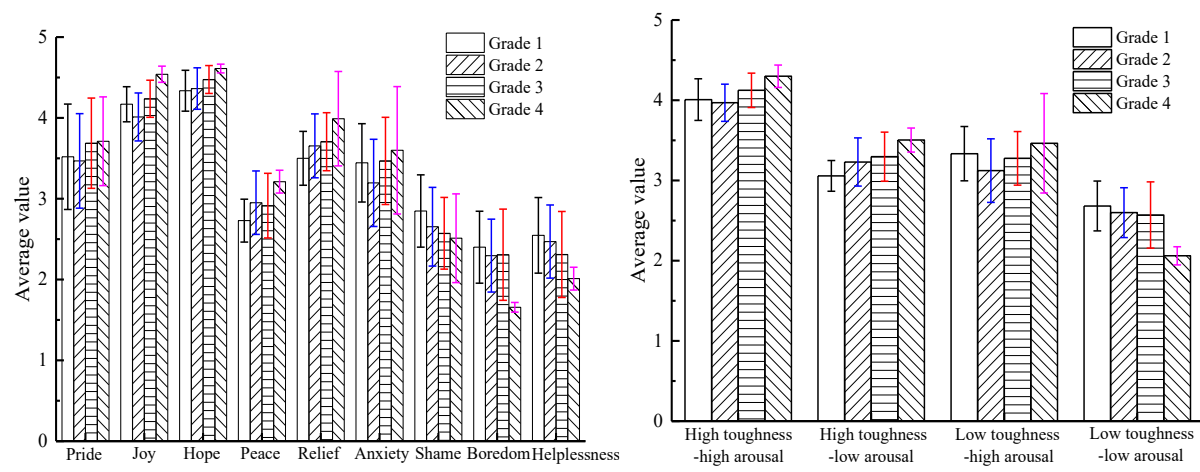

d) Grade factor

Fig. 3. Influence of various factors on college students' academic emotion and psychological resilience 


\section{Correlation between Emotional Control and Mental Health Management}

\subsection{Objectives and methods}

Figure 4 gives the content of the emotional control ability model, including emotional perception ability, emotional evaluation ability, emotional regulation selfefficacy, effective application of emotional regulation strategies, emotional regulation ability, and emotional regulation reflection ability. Emotional evaluation ability requires college students to be able to make reasonable assessments based on identifying their own emotions $[24,25]$. The effective application of emotional regulation strategies requires college students to consciously and flexibly apply the corresponding methods to cope with their own emotional changes [26, 27]. The emotional regulation self-efficacy is the level of confidence of college students for regulating their emotions effectively [28-30]. In this study, it's assumed that there're differences in the emotional control and mental health management of college students of different genders, grades, and identity (cadre or not). Table 2 lists the basic information of the subjects. All subjects are college students from Nanchang University in Jiangxi. The total score is 60 points.

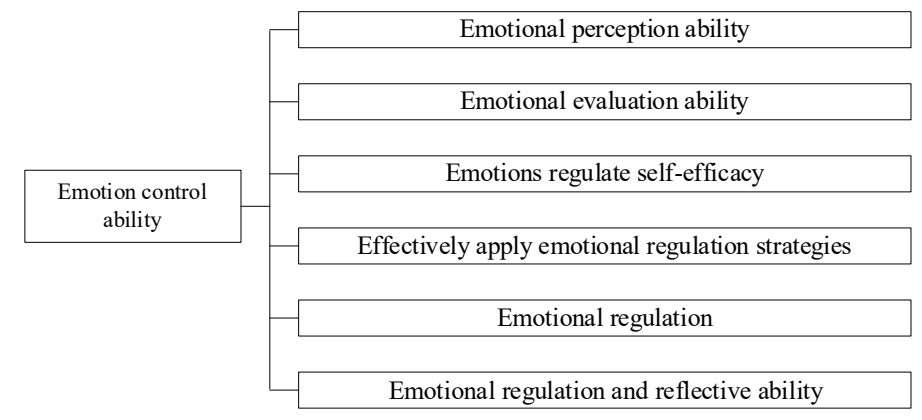

Fig. 4. The emotional control ability model

Table 2. Basic information of subjects

\begin{tabular}{|l|c|c|c|}
\hline Variable & Category & Number & Percentage/\% \\
\hline \multirow{3}{*}{ Gender } & Male & 166 & $51.39 \%$ \\
\hline \multirow{3}{*}{ Student cadre } & Female & 157 & $48.61 \%$ \\
\hline \multirow{4}{*}{ Grade } & Yes & 59 & $18.27 \%$ \\
\cline { 2 - 4 } & No & 264 & $81.73 \%$ \\
\cline { 2 - 4 } & First grade & 66 & $20.43 \%$ \\
\cline { 2 - 4 } & Second grade & 84 & $26.01 \%$ \\
\cline { 2 - 4 } & Third grade & 92 & $28.48 \%$ \\
\cline { 2 - 4 } & Fourth grade & 81 & $25.08 \%$ \\
\hline
\end{tabular}




\subsection{Modeling of emotional control and mental health management}

Emotional control is the regulation of individual emotions through self-efficacy, which can affect people's mental activities and behaviors [31]. When facing victories or experiencing pleasant things, people will express the corresponding positive emotions and their confidence for happy experiences, which is called the positive emotional control $[32,33]$. However, when facing failures, adverse situations, or experiencing unpleasant things, people will express angry or depressed emotions, they believe they can increase their confidence for improving the negative emotions, and this is called the negative emotional control [34]. Figure 5 shows the research results of the emotional control self-efficacy of college students. Apparently, their negative emotional control self-efficacy has the highest score, indicating that college students generally have a good ability to control their negative emotions. The results given in Figure 5 are the average values of college students' emotional control of all factors. By analyzing the obtained research results, we found that all factors (gender, cadre or not, grade) have a positive influence on college students' emotional control, and the effect on emotional control of higher-grade students is better than that of lower-grade students.

Figure 6 shows the research results of college students' mental health management self-efficacy. The personal strength self-efficacy has the highest score, followed by the support self-efficacy. By analyzing the mental health management self-efficacy of college students of different genders, we found that, in terms of goal-focus selfefficacy, emotional control self-efficacy, and personal strength self-efficacy, the average scores of male students are higher than those of female students; while in terms of interpersonal assistance self-efficacy and support self-efficacy, the average scores of female students are higher than those of male students.

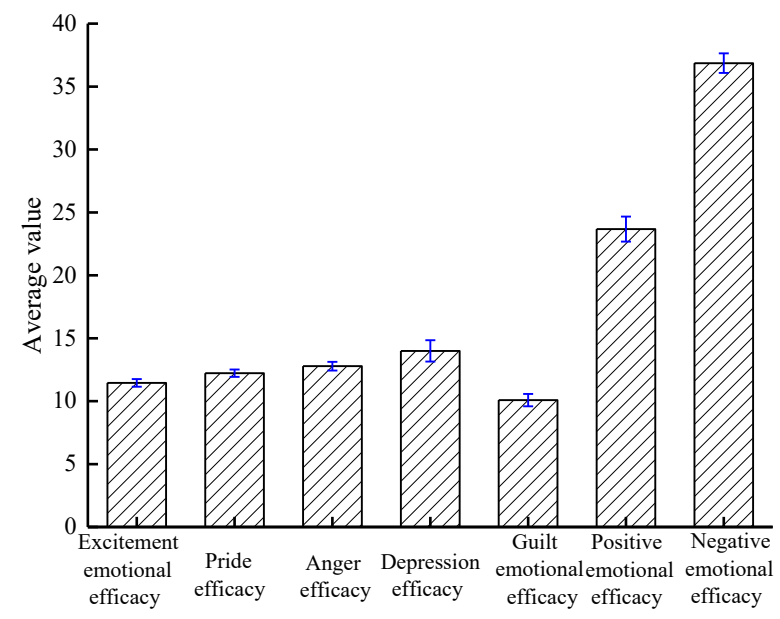

Fig. 5. Research results of the emotional control self-efficacy of college students 


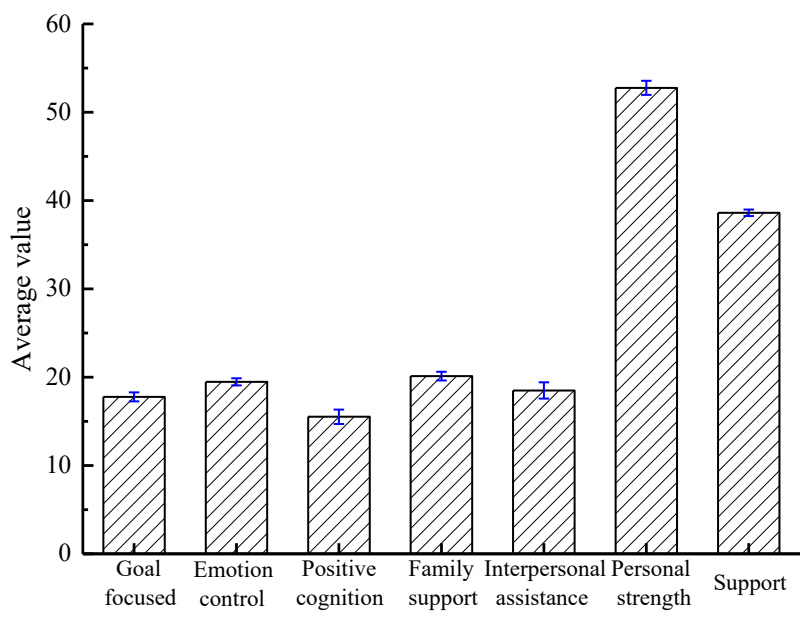

Fig. 6. Research results of college students' mental health management self-efficacy

\section{Influence of Music Intervention on Emotional Control and Mental Health Management Self-efficacy}

\subsection{Influence of music intervention on the emotional control self-efficacy of college students}

Deep-level emotional control includes the regulation and repair of emotions, and there are individual differences in the emotional regulation ability of different college students. Students with a good emotional regulation ability can better adopt positive emotional regulation strategies to cope with their negative emotions, which is conducive to maintaining a good mental health level. Music can make people happy and forget their worries, so it has a positive influence on the emotional control of college students. The process of musical intervention is complex and is not completed by a single psychological mechanism; it includes brainstem reflexes, evaluative conditioned reflexes, emotional contagion, visual images, episodic memory, and musical expectation, etc. Music intervention can regulate emotions, especially sad music. When people who feel sad are listening to sad music, it will make human body produce calming and comforting hormones. Medical research also revealed that happy music can activate the both-side ventral striatum and left-side dorsal striatum of the listener's brain; sad music can activate the hippocampus and auditory contact area of the brain; and neutral music can activate the left gyrus and auditory contact area of the brain.

To figure out the influence of music on college students' emotional control selfefficacy, in this study, five positive music clips and five negative music clips were selected for the experiment. Every time the subjects finished the listening of a music clip, they were asked to fill in an emotional state questionnaire and a mental health state questionnaire; then, they took a three-minute break and continued to listen to the 
next music clip; the positive and negative music clips were played randomly. The measurement of emotional control adopted a nine-dimension scale, higher scores indicate that the emotions induced by the music tend to be positive emotions, and lower scores indicate that these emotions tend to be negative emotions. Figure 7 shows the influence of positive music on college students' emotional control, as can be seen from the figure, positive music has a positive influence on positive emotional control, and positive music can better mobilize positive emotions. Figure 8 shows the influence of negative music on college students' emotional control, as can be seen from the figure, negative music has greatly increased the helplessness dimension of college students; in terms of the anxiety dimension and the boredom dimension, there're both increase and decrease, indicating that negative music has both controlling and enhancing effects on negative emotions of college students

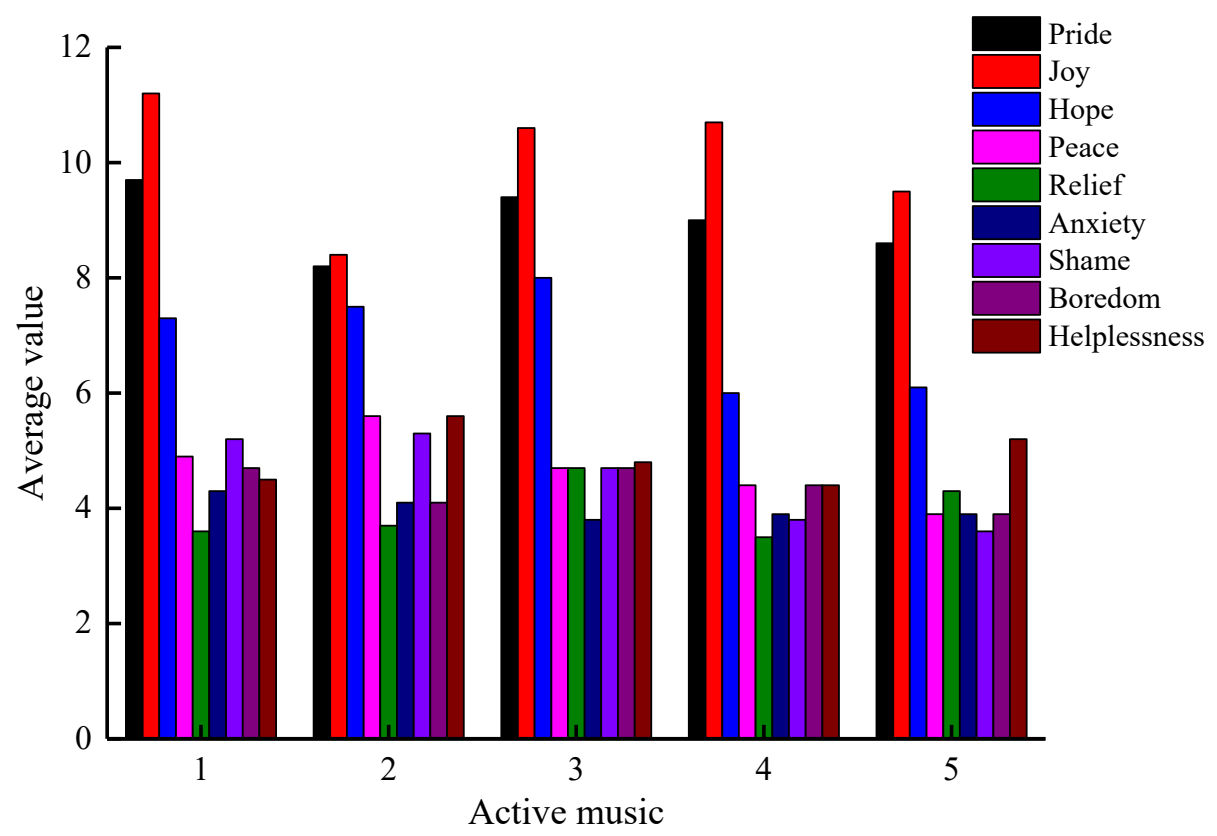

Fig. 7. Influence of positive music on college students' emotional control 


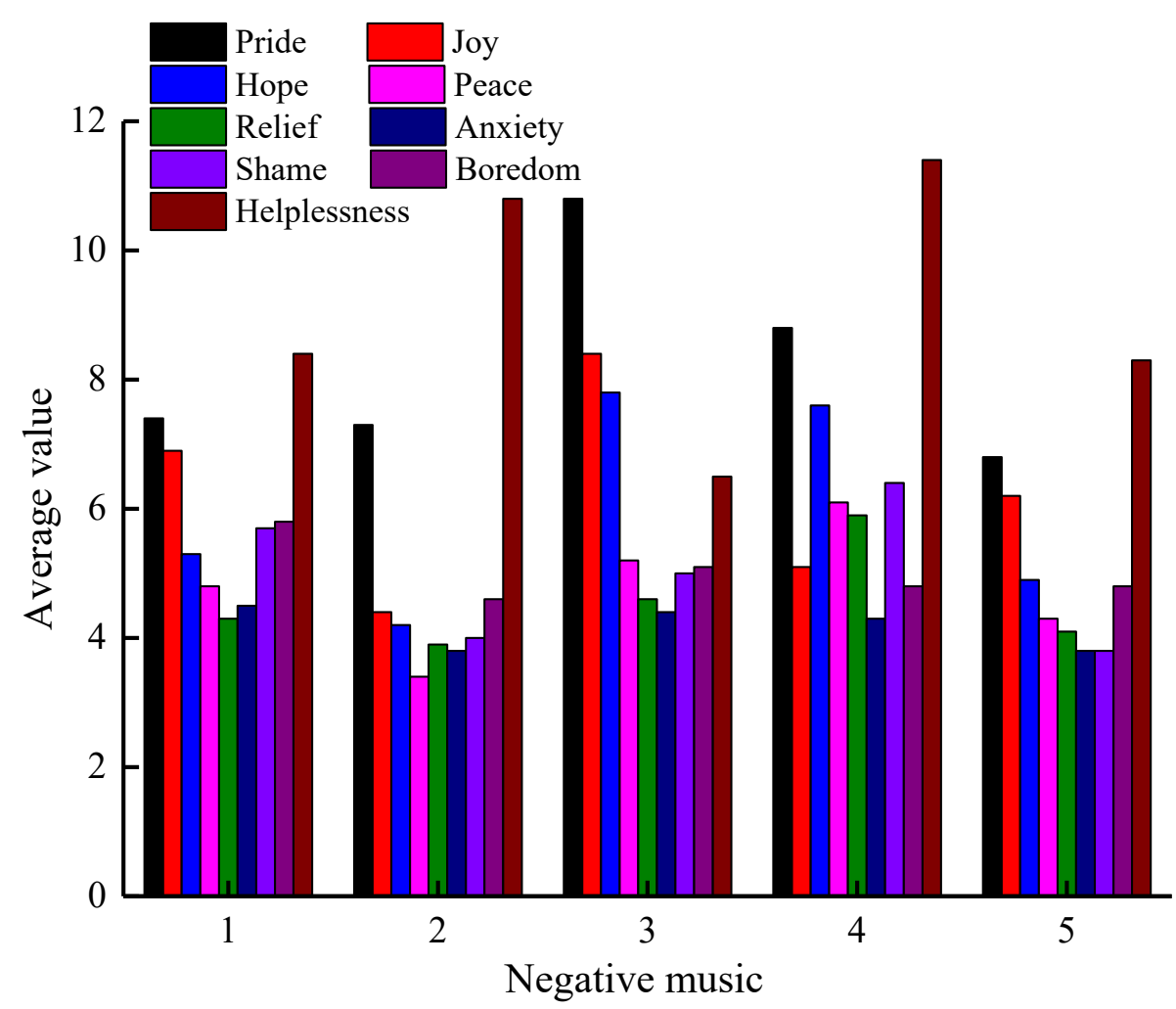

Fig. 8. Influence of negative music on college students' emotional control

\subsection{Influence of music intervention on the mental health management self- efficacy of college students}

Music is an effective way to improve the mental health of college students, and music therapy has a good effect on improving students' mental quality and mental health. The experiment method is the same with that of Section 4.1, the score of arousal level is the average score of all subjects, and higher scores indicate higher mental health level induced by the music; the higher the score, the higher the score of pleasantness, and the higher the mental health level induced by the music. Figure 9 shows the evaluation of the level of pleasantness and arousal of the ten music clips. In terms of the pleasantness level dimension, there're significant differences in the influence of the ten music clips on college students' mental health management selfefficacy; while in terms of the arousal level dimension, there's no significant difference in the influence of the ten music clips on college students' mental health management self-efficacy. 


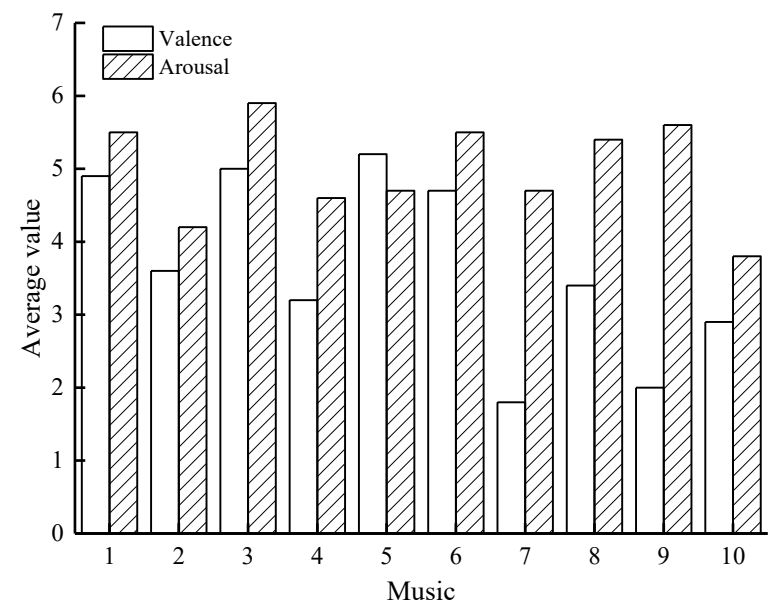

Fig. 9. Evaluation of the level of pleasantness and arousal of ten music clips

\section{Conclusions}

This paper took college students as subjects to explore the influence of music intervention on college students' emotional control and mental health management selfefficacy, and obtained the following conclusions:

1. College students' academic emotions and psychological resilience are significantly influenced by their gender, family situation, grade, and whether they are student cadres or not. The scores of positive academic emotions are higher than those of negative academic emotions, and on the whole, current college students' psychological resilience is at an average level.

2. Positive music has a positive effect on the control of positive emotions; positive music can better mobilize positive emotions, while negative music can both control and enhance the negative emotions of college students.

3. In terms of pleasantness level dimension, there're significant differences in the influence of ten music clips selected in the study on college students' mental health management self-efficacy, while in terms of the arousal level dimension, there's no significant difference.

\section{$6 \quad$ References}

[1] Hantk, N.C., Gyurak, A., Moorleghem, K.V., Waring, J.D., Adamson, M.M., O'Hara, R., Beaudreau, S.A. (2016). Disentangling cognition and emotion in older adults: the role of cognitive control and mental health in emotional conflict adaptation. International Journal of Geriatric Psychiatry, 32(8): 840-848. https://doi.org/10.1002/gps.4535

[2] Mbna, B., Jhba, C., Rwa, B., Tpa, B. (2020). Does cognitive behavioural therapy or mindfulness-based therapy improve mental health and emotion regulation among men who perpetrate intimate partner violence? A randomised controlled trial - sciencedirect. Interna- 
Paper-Influence of Music Intervention on Emotional Control and Mental Health Management...

tional Journal of Nursing Studies, 113: 103795. https://doi.org/10.1016/j.ijnurstu. $\underline{2020.103795}$

[3] Greaves, C.E., Parker, S.L. Zacher, H., Jimmieson, N.L. (2017). Working mothers' emotional exhaustion from work and care: the role of core self-evaluations, mental health, and control. Work \& Stress, 31(2): 164-181. https://doi.org/10.1080/02678373.2017. 1303760

[4] Chaidi, I., Drigas, A. (2020). Autism, Expression, and Understanding of Emotions: Literature Review, International Journal of Online and Biomedical Engineering, 16(2): 94-111. https://doi.org/10.3991/ijoe.v16i02.11991

[5] Bakola, L.N., Drigas, A. (2020). Technological Development Process of Emotional Intelligence as a Therapeutic Recovery Implement in Children with ADHD and ASD Comorbidity, International Journal of Online and Biomedical Engineering, 16(3): 75-85. https://doi. org/10.3991/ijoe.v16i03.12877

[6] Slew, M.N., Ke, G.N., Raymond, W. (2014). The mediating role of work locus of control on the relationship among emotional intelligence, organisational citizenship behaviours, and mental health among nurses. Australian Journal of Psychology, 66(4): 207-215. https://doi.org/10.1111/ajpy.12049

[7] Huang, Y.H., Du, P.L., Chen, C.H., Yang, C.A., Huang, I.C. (2011). Mediating effects of emotional exhaustion on the relationship between job demand-control model and mental health. Stress and Health, 27(2): E94-E109. https://doi.org/10.1002/smi.1340

[8] Burns, S.M., Mahalik, J.R. (2006). Physical health, self-reliance, and emotional control as moderators of the relationship between locus of control and mental health among men treated for prostate cancer. Journal of Behavioral Medicine, 29(6): 561-572. https://doi.org/10.1007/s10865-006-9076-1

[9] Thorlacius, O., Gudmundsson, E. (2018). The effectiveness of the children's emotional adjustment scale (ceas) in screening for mental health problems in middle childhood. School Mental Health, 11(3): 400-412. https://doi.org/10.1007/s12310-018-9296-x

[10] Cairns, A.J., Kavanagh, D.J., Dark, F, Mcphail, S.M. (2019). Goal setting improves retention in youth mental health: a cross-sectional analysis. Child \& Adolescent Psychiatry \& Mental Health, 13(1): 31. https://doi.org/10.1186/s13034-019-0288-x

[11] Diab, M., Peltonen, K., Qouta, S.R., Palosaari, E., Punamki, R.L. (2017). Can functional emotion regulation protect children's mental health from war trauma? A Palestinian study. International Journal of Psychology: Journal International de Psychologie, 54(1): 42-52. https://doi.org/10.1002/ijop.12427

[12] Wang, S.Y. (2021). Online learning behavior analysis based on image emotion recognition. Traitement du Signal, 38(3): 865-873. https://doi.org/10.18280/ts.380333

[13] Dondeti, V., Bodapati, J.D., Shareef, S.N., Naralasetti, V. (2020). Deep convolution features in non-linear embedding space for fundus image classification. Revue d'Intelligence Artificielle, 34(3): 307-313. https://doi.org/10.18280/ria.340308

[14] Perez, C.M., Nicholson, B.C., Dahlen, E.R., Leuty, M. (2017). Overparenting and emerging adults' mental health: the mediating role of emotional distress tolerance. Journal of Child and Family Studies, 29(2): 374-381. https://doi.org/10.1007/s10826-019-01603-5

[15] Nhi, T.T., Hanh, N.T.T., Gammeltoft, T.M. (2018). Emotional violence and maternal mental health: a qualitative study among women in northern vietnam. BMC Women $\backslash$ "s Health, 18(1): 58. https://doi.org/10.1186/s12905-018-0553-9

[16] Wilski, M., Brola, W., Tomczak, M. (2019). Health locus of control and mental health in patients with multiple sclerosis: mediating effect of coping strategies. Research in Nursing \& Health, 42(4): 296-305. https://doi.org/10.1002/nur.21955 
Paper-Influence of Music Intervention on Emotional Control and Mental Health Management...

[17] Li, E.T., Carracher, E., Bird, T. (2019). Linking childhood emotional abuse and adult depressive symptoms: the role of mentalizing incapacity - sciencedirect. Child Abuse \& Neglect, 99: 104253. https://doi.org/10.1016/i.chiabu.2019.104253

[18] Predatu, R., David, D.O., Maffei, A. (2020). Beliefs about emotions, negative metaemotions, and perceived emotional control during an emotionally salient situation in individuals with emotional disorders. Cognitive Therapy and Research, 44(2): 287-299. https://doi.org/10.1007/s10608-019-10064-5

[19] Kovess-Masfety, V., Evans-Lacko, S., Williams, D., Andrade, L.H., Gureje, O. (2017). The role of religious advisors in mental health care in the world mental health surveys. Social Psychiatry and Psychiatric Epidemiology, 52(3): 353-367. https://doi.org/10.1007/ s00127-016-1290-8

[20] Schweizer, S., Parker, J., Leung, J.T., Griffin, C., Blakemore, S. J. (2019). Age-related differences in affective control and its association with mental health difficulties. Development and Psychopathology, 32(1): 329-341. https://doi.org/10.1017/S095457 $\underline{9419000099}$

[21] Li, Y.F. (2020). Application of Computer-Based Auto Accompaniment in Music Education, International Journal of Emerging Technologies in Learning, 15(6): 140-151.

[22] Yang, L.Q. (2020). Comprehensive Evaluation of Music Course Teaching Level Based on Improved Multi-attribute Fuzzy Evaluation Model, International Journal of Emerging Technologies in Learning, 15(9): 107-121. https://doi.org/10.3991/ijet.v15i19.17411

[23] Russell, R.D., Black, L.J., Pham, N.M., Begley, A. (2020). The effectiveness of emotional wellness programs on mental health outcomes for adults with multiple sclerosis: a systematic review and meta-analysis. Multiple Sclerosis and Related Disorders, 44: 102171. https://doi.org/10.1016/j.msard.2020.102171

[24] Bram, A.D., Gottschalk, K.A., Leeds, W.M. (2019). Chronic fatigue syndrome and the somatic expression of emotional distress: applying the concept of illusory mental health to address the controversy. Journal of Clinical Psychology, 75(1): 116-131. https://doi.org/10. $\underline{1002 / j \operatorname{clp} .22692}$

[25] Rpa, B., Dodbc, D., Am, E. (2019). The effects of irrational, rational, and acceptance beliefs about emotions on the emotional response and perceived control of emotions. Personality and Individual Differences, 155: 109712. https://doi.org/10.1016/j.paid.2019. 109712

[26] Frajo-Apor, B., Pardeller, S., Kemmler, G., Hofer, A. (2016). Emotional intelligence and resilience in mental health professionals caring for patients with serious mental illness. Psychology, health \& medicine, 21(6): 755-61. https://doi.org/10.1080/13548506.2015. $\underline{1120325}$

[27] Hou, W.K., Bonanno, GA. (2018). Emotions in everyday life during social movements: prospective predictions of mental health. Journal od Counseling Psychology, 65(1): 120131. https://doi.org/10.1037/cou0000236

[28] Schleider, J.L., Weisz, J.R. (2018). Parent expectancies and preferences for mental health treatment: the roles of emotion mind-sets and views of failure. Journal of clinical child and adolescent psychology, 47(Suppl 1): S480-S496. https://doi.org/10.1080/15374416. 2017.1405353

[29] Leis, J.A., Heron, J., Stuart, E.A., Mendelson, T. (2014). Associations between maternal mental health and child emotional and behavioral problems: does prenatal mental health matter? Journal of Abnormal Child Psychology, 42(1): 161-171. https://doi.org/10.1007/ s10802-013-9766-4 
Paper-Influence of Music Intervention on Emotional Control and Mental Health Management...

[30] Fernandez-Abascal, E.G., Martin-Diaz, M.D. (2015). Dimensions of emotional intelligence related to physical and mental health and to health behaviors. Frontiers in Psychology, 6: 317. https://doi.org/10.3389/fpsyg.2015.00317

[31] Vohra, S., Punja, S., Sibinga, E., Baydala, L., Wikman, E., Singhal, A., Dolcos, F., Vliet, K.J.V. (2019). Mindfulness-based stress reduction for mental health in youth: a cluster randomized controlled trial. Child and Adolescent Mental Health, 24(1): 29-35. https://doi.org/10.1111/camh.12302

[32] Fitzsimons, E., Goodman, A., Kelly, E., Smith, J.P. (2017). Poverty dynamics and parental mental health: determinants of childhood mental health in the UK. Social Science \& Medicine, 175: 43-51. https://doi.org/10.1016/j.socscimed.2016.12.040

[33] Scanlan, J.N., Still, M. (2019). Relationships between burnout, turnover intention, job satisfaction, job demands and job resources for mental health personnel in an Australian mental health service. BMC Health Services Research, 19(1): 62. https://doi.org/10.1186/ s12913-018-3841-Z

[34] Louisa, H., Joke, B., Thomas, S., Stefan, K, Zhang, Q. (2017). Effects of music therapy and music-based interventions in the treatment of substance use disorders: a systematic review. Plos One, 12(11): 1-36. https://doi.org/10.1371/journal.pone.0187363

\section{$7 \quad$ Author}

Xiujun Xu, currently an associate professor in the Music Department of Shijiazhuang Preschool Teachers College, graduated from Hebei Normal University, researching music education, published more than 20 papers in journals above the provincial level, presided over or participated in research on many provincial-level topics, editor-in-chief Or participated in the compilation of music education textbooks "Music Comprehensive Course", "Vocal Music", "Musical Theory Sight Singing and Ear Training", etc. In 2018, he was awarded the title of "Professional Leader" in Shijiazhuang City.

Article submitted 2021-08-25. Resubmitted 2021-09-27. Final acceptance 2021-09-29. Final version published as submitted by the author. 